\title{
A homozygous point mutation in the GH1 promoter (c.-223C $>$ T) leads to reduced GH1 expression in siblings with isolated GH deficiency (IGHD)
}

\author{
João L O Madeira1, Alexander A L Jorge1,2, Regina M Martin1, \\ Luciana R Montenegro', Marcela M Franca', Everlayny F Costalonga', \\ Fernanda A Correa', Aline P Otto', Ivo J P Arnhold', Helayne S Freitas ${ }^{3}$, \\ Ubiratan F Machado ${ }^{3}$, Berenice B Mendonca ${ }^{1}$ and Luciani R Carvalho ${ }^{1}$ \\ 'Unidade de Endocrinologia do Desenvolvimento, Laboratório de Hormônios e Genética Molecular \\ LIM/42, ${ }^{2}$ Unidade de Endocrinologia-Genética - LIM/25, Disciplina de Endocrinologia da Faculdade de \\ Medicina da Universidade de São Paulo (FMUSP), São Paulo, Brazil and ${ }^{3}$ Laboratório de Metabolismo \\ e Endocrinologia do Departamento de Fisiologia e Biofísica do Instituto de Ciências Biomédicas da \\ Universidade de São Paulo (ICB-USP), São Paulo, Brazil
}

\author{
Correspondence \\ should be addressed \\ to L R Carvalho \\ Email \\ lucianic@gmail.com
}

\begin{abstract}
Context: Mutations in the GH1 promoter are a rare cause of isolated growth hormone deficiency (IGHD).

Objective: To identify the molecular aetiology of a family with IGHD.

Design: DNA sequencing, electromobility shift (EMSA) and luciferase reporter assays.

Setting: University Hospital.

Patients: Three siblings (2M) born to consanguineous parents presented with IGHD with normal pituitary on MRI.

Methods: The GH1 proximal promoter, locus control region, five exons and four introns as well as GHRHR gene were sequenced in genomic DNA by Sanger method. DNA-protein interaction was evaluated by EMSA in nuclear extracts of GH3 pituitary cells. Dual-luciferase reporter assays were performed in cells transiently transfected with plasmids containing four different combinations of GH1 allelic variants (AV).

Results: The patients harboured two homozygous variants (c.-185T>C and c.-223C $>T$ ) in the GH1 promoter within a highly conserved region and predicted binding sites for POU1F1/SP1 and SP1 respectively. The parents and brother were carriers and these variants were absent in 100 controls. EMSA demonstrated absent binding of GH3 nuclear extract to the c.-223C $>T$ variant and normal binding of both POU1F1 protein and GH3 nuclear extract to the C.-185T>C variant. In contrast to GH1 promoter with AV only at c.-185, the $\mathrm{GH} 1$ promoter containing the AV only at c.-223 and at both positions drove significantly less expression of luciferase compared with the promoter containing either positions wild type in luciferase reporter assays. Conclusion: To our knowledge, c.-223C > T is the first homozygous point mutation in the GH1 promoter that leads to short stature due to IGHD.
\end{abstract}

\section{Introduction}

Circulating growth hormone (1) is secreted by the anterior pituitary and represents one of the most important hormonal regulators of postnatal linear growth. GH is
() 2016 European Society of Endocrinology Printed in Great Britain encoded by the human growth hormone 1 gene (GH1; $\mathrm{OMIM}^{*} 139250$ ), which consists of five exons on the long arm of chromosome 17 (17q23.3-24.2). GH1 lies within a 
cluster of $66 \mathrm{~kb}$ containing four other highly homologous genes: CSH1, CSH2, CSHP1 and GH2 (2).

GH1 was the first gene to be associated with isolated GH deficiency (IGHD) (3). Patients with IGHD are mainly characterised by growth failure with maxillary hypoplasia, forehead prominence and central obesity. Approximately, $11 \%$ of IGHD cases are familial (4), and four different types of familial IGHD have been identified based on their inheritance patterns: two autosomal recessive (Type IA and IB), one autosomal dominant (Type II) and one X-linked (Type III) (4). IGHD type IB has been associated with recessive mutations within $G H 1$ or GHRHR, without the development of inactivating antibodies (4).

GH1 expression is regulated by a proximal promoter region and a distal locus control region (LCR) located $15 \mathrm{~kb}$ upstream of the first transcription site. The promoter region is highly polymorphic, and at least 16 single nucleotide polymorphisms (SNPs) have been reported within a 535-basepair segment upstream of the transcription start site $(5,6,7)$. The interaction between the promoter region and activating transcription factors (such as POU1F1 and NF1) or repressive factors (such as SP1) leads to the activation or repression of GH1 expression respectively $(8,9,10,11)$.

Although several studies have investigated the effect of SNPs and mutations in the promoter region on $G H 1$ expression in both healthy and affected individuals $(5,12$, $13,14,15,16,17,18)$, a mutation in the promoter region leading to IGHD with complete penetrance has never been described. This study describes a double homozygous allelic variant (c.-223C >T and c.-185T>C) in the GH1 promoter region in a consanguineous family with severe isolated GH deficiency. Analysis of this variant suggests that only the c.-223C $>\mathrm{T}$ mutation is responsible for the phenotype, expanding the spectrum of known molecular defects responsible for IGHD type IB.

\section{Materials and methods}

All participants and controls gave their written informed consent for genetic analyses, which were approved by the Ethical Committee of Hospital das Clinicas - HCFMUSP. The control population consisted of 100 Brazilian adults from whom 30 were male and 70 were female, all older than 20years old, with normal height ranging from -2.0 to +2.8 SDS.

\section{Hormone assays}

Glucose and growth hormone were measured under basal conditions and 15, 30, 45, 60, and $90 \mathrm{~min}$ after insulin injection $(0.1 \mathrm{U} / \mathrm{kg})$. $\mathrm{GH}$ was measured by an immunoradiometric (IRMA) assay with polyclonal antibodies or by an immunofluorometric (IFMA) method with monoclonal antibodies (AutoDELFIA, Wallac, Turku, Finland). The assays were standardised to international standard 80/505 of the World Health Organization, and concentrations from 0.1 to $38 \mu \mathrm{g} / \mathrm{L}$ presented an inter-assay coefficient of variation $<10 \%$. GHD was considered when $\mathrm{GH}$ peaks after both clonidine and hypoglycaemia stimulation tests were less than $7 \mu \mathrm{g} / \mathrm{L}$ as measured by IRMA or less than $3.3 \mu \mathrm{g} / \mathrm{L}$ as measured by IFMA (19). Basal IGF-1 concentration was determined by radioimmunoassay after ethanol extraction (DSL, Webster, TX, USA), and basal IGFBP-3 concentration was measured by IRMA (DSL, Webster, TX, USA). The interassay coefficient of variation was $<10 \%$ for IGF- 1 from 18 to $500 \mu \mathrm{g} / \mathrm{L}$ and for IGFBP-3 from 0.14 to $12 \mathrm{mg} / \mathrm{L}$.

\section{DNA analysis}

Genomic DNA was extracted from peripheral leukocytes using standard procedures. The proximal promoter, locus control region, five exons and four introns of $G H 1$ and the flanking regions were amplified by PCR (Supplementary Table 2, see section on supplementary data given at the end of this article) and directly sequenced by the Sanger method, covering the entire genomic sequence of $\mathrm{GH} 1$ (reference sequence: NT_010783.15: from 27270352 to $27268713 \mathrm{bp}$ ). GHRHR (cDNA reference sequence: NM_000823.3) was also amplified as described in a previous report (20).

\section{Plasmid constructs}

The parents' DNA harbouring heterozygous mutations was used as a template for plasmid construction. One set of primers used to amplify a 611 bp region (c.-667 to c.-56, NT_010783.15 of GH1) was designed with modifications to incorporate restriction enzyme sites for Sac I (5'-AAA GGG GAG AGC TCG TGT G-3') and Bgl II (5'-GGA TCT CTT GTC CTT GAG CAG A-3'). The PCR product was extracted from the gel and purified using a resin column (Qiagen). The purified 611 bp PCR fragment was cloned into the TOPO TA vector (Invitrogen) according to the manufacturer's instructions. The PCR product was released from TOPO TA using the Sac I and Bgl II restriction enzymes. The digested products were submitted to electrophoresis in a 1\% agarose gel. The $611 \mathrm{bp}$ insert was extracted and purified using a resin 
column (Qiagen) and then sub-cloned into the PGL3 basic luciferase vector (Promega).

To evaluate the functional consequences of each allelic variant, four different plasmids were constructed: one containing both sites wild type (-223WT/-185WT), one containing both sites with the allelic variants $(-223 \mathrm{AV} /-$ $185 \mathrm{AV})$, one containing the allelic variant only at position c.-223 (-223AV/-185WT) and the last one containing the allelic variant only at c.-185 (-223WT/-185AV).

\section{Cell culture}

The immortalised anterior pituitary cell line GH3 was employed in the transfection studies. We used either the GH3 cell line, which was a gift from Dr Audrey Seasholtz at the University of Michigan, MI, USA, or the GH3 cell line, bought from Banco de Células do Rio de Janeiro (BCRJ) (Catalogue Number 0090, Banco de Células do Rio de Janeiro, Duque de Caxias, RJ, Brazil). The cells were maintained at $37^{\circ} \mathrm{C} / 5 \% \mathrm{CO}_{2}$ in Dulbecco's modified Eagle medium (Invitrogen) supplemented with $10 \%$ heat-inactivated foetal bovine serum (Hyclone, Logan, UT, USA) and $1 \times$ antifungal and antimicrobial agent ( $100 \mathrm{units} / \mathrm{mL}$ penicillin, $100 \mu \mathrm{g} / \mathrm{mL}$ streptomycin, and $250 \mathrm{ng} / \mathrm{mL}$ Amphotericin B) from Invitrogen.

\section{Transient transfection and dual-luciferase reporter assays}

Cells were plated in 24-well plates (Thermo Fisher Scientific) at a density of $2.5 \times 10^{4}$ cells/well, such that the cells were $60-80 \%$ confluent the next day. DNA cocktail was added up to $2 \mu \mathrm{g} /$ well $(0.5-2 \mu \mathrm{g}$ pGH1 luciferase, $0.001-0.01 \mu \mathrm{g}$ CMV-Renilla internal control and basic pGL3 expression vector ranging from 0.5 to $2 \mu \mathrm{g}$ per well to normalise at $1 \mu \mathrm{g}$ DNA/well). Cells were transfected in $500 \mu \mathrm{L}$ serum-free DMEM using JetPEI transfection reagent (Polyplus transfection, Illkirch, France) at a ratio 3:1 according to the manufacturer's protocol. Basic pGL3 plasmid driving the luciferase reporter gene was used as a negative control and considered the basal level. Dual-luciferase assays (Promega) were performed according to the manufacturer's protocol and measured using a luminometer with a Synergy HT 96 well plate reader (BioTek). The assays were read after $48 \mathrm{~h}$. The results were normalised to the CMV-Renilla luciferase internal control. All assays were performed in triplicate and repeated at least three times. The results were averaged and expressed as the fold change over the control vector.

\section{Nuclear extract}

GH3 cells were incubated in a $75 \mathrm{~cm}^{2}$ flask to $80 \%$ confluence. Afterwards, the cells were washed twice with ice-cold PBS (10 mM sodium phosphate, pH 7.4, $150 \mathrm{mM}$ $\mathrm{NaCl})$, and $410 \mu \mathrm{L}$ of lysis buffer was added $(100 \mathrm{mM}$ Tris, pH 7.5, containing $10 \mathrm{mM}$ EDTA, $10 \mathrm{mM}$ sodium fluoride $10 \mathrm{mM}, 100 \mathrm{mM}$ sodium 11 pyrophosphate, $1 \%$ Nonidet P-40 (octyl phenoxypolyethoxylethanol), 1\% sodium deoxicholate, $2 \mathrm{mM} \mathrm{Na}_{3} \mathrm{VO}_{4}, 10 \mathrm{mM} \mathrm{NaF}, 1 \mathrm{mM}$ PMSF, and $1 \times$ protease inhibitor cocktail; mini complete tablets, Roche). The cells were scraped from the bottom of the flask and transferred to an Eppendorf tube. The tube was placed on ice shaking for $1 \mathrm{~h}$. Subsequently, the tube was centrifuged at $14000 \mathrm{~g}$ for $20 \mathrm{~min}$ at $4^{\circ} \mathrm{C}$, and the supernatant was aliquoted into a cryotube and stored at $-80^{\circ} \mathrm{C}$.

\section{Electrophoretic mobility shift assays (EMSAs)}

Nuclear extracts from GH3 pituitary cells were used as a source of nuclear transcriptional factors to evaluate the functional relevance of the c.-223C $>\mathrm{T}$ and c.-185T $>\mathrm{C}$ variants. Four oligonucleotides were designed to contain the wild type or the c.-223C $>\mathrm{T} \quad(-223 \mathrm{WT}$ and $-223 \mathrm{AV}$ respectively) or c. $-185 \mathrm{~T}>\mathrm{C}(-185 \mathrm{WT}$ and $-185 \mathrm{AV})$ variants (Supplementary Table 3). The constructs were labelled with $\mathrm{P}^{32}$ as described previously (21). The sense probe and complementary labelled probes were annealed to produce double-stranded DNA. To assess POU1F1 binding specificity to $-185 \mathrm{WT}$ and $-185 \mathrm{AV}$, mouse monoclonal antibody anti-POU1F1 (Catalogue Number ab 10623, Abcam) and a non-specific antibody anti-HNF-1 $\alpha$ (Catalogue Number SC-6547 Santa Cruz Biotechnology) were used in addition to purified POU1F1 protein (Catalogue Number ab114764, Abcam).

Binding reactions of the probes (30 000c.p.m.) were performed by incubating $15 \mu \mathrm{g}$ protein from a GH3 cell nuclear extract at room temperature for $30 \mathrm{~min}$ in $20 \mu \mathrm{L}$ binding buffer consisting of $20 \mathrm{mM}$ HEPES, pH 7.6, $50 \mathrm{mM} \mathrm{KCl}, 10 \%$ glycerol, $0.2 \mathrm{mM}$ EDTA, $1 \mathrm{mM}$ DTT and $2 \mu \mathrm{g}$ polydeoxyinosinic-deoxycytidylic acid poly[dI-dC] (Amersham Pharmacia Biotech).

The DNA-protein complexes were electrophoresed on $4 \%$ non-denaturing polyacrylamide gels at $4^{\circ} \mathrm{C}$ in $45 \mathrm{mM}$ Tris, $45 \mathrm{mM}$ borate and $1 \mathrm{mM}$ EDTA buffer. The gels were 
dried and subjected to autoradiography. Competitive binding assays were conducted under the same conditions, with the addition of 250- to 1500 -fold molar excess of unlabelled oligonucleotides. To determine the specific band in the EMSA, an anti-POU1F1 antibody and a nonspecific antibody (anti-HNF-1 $\alpha$ ) were pre-incubated with GH3 nuclear extracts for $90 \mathrm{~min}$ in binding buffer. After the pre-incubation of nuclear extract and anti-POU1F1, the labelled probes were added to the complex.

\section{Bioinformatic analysis}

Putative binding sites in the GH1 promoter region were predicted using Alibaba 2.1 (http://www.gene-regulation. com/pub/programs/alibaba2/index.html).

\section{Statistical analysis}

SigmaStat version 3.5 (Systat Software Inc, Chicago, IL, USA) was used for data analysis. Comparisons between two groups were performed using Student's $t$-tests or MannWhitney tests where appropriate. Bonferroni adjustment was employed for multiple testing, and a value of $P<0.05$ was considered significant. The data are presented as the mean and standard deviation (s.D.).

\section{Results}

\section{Clinical features}

Three siblings ( 2 males) born to consanguineous parents were referred to our department due to short stature. Their parents are first cousins and have short stature (father's height SDS $=-2.3$, mother's height $\mathrm{SDS}=-2.5$ ). The patients have a brother with normal height (brother's height SDS $=-1.5$ ). The affected siblings had proportionate severe postnatal short stature at first visit, with height SDSs ranging from -4.1 to -5.8 (Fig. 1). When first evaluated, they had low IGF-1 and IGFBP-3 levels, decreased GH response to insulin tolerance tests (GH peak ranging from 3.5 to $4.8 \mu \mathrm{g} / \mathrm{L}$, polyclonal antibody IRMA) and normal TSH, cortisol, prolactin and gonadotrophin levels (Supplementary Table 1). The oldest sibling (II.1) was treated for a short duration with low doses of pituitary-GH $(0.1 \mathrm{mg} / \mathrm{kg} /$ week divided into equal daily doses given 3 days/week), and his final height was $145 \mathrm{~cm}$ (height SDS $=-4.5$ ). His sister (II.2) achieved a final height of $137 \mathrm{~cm}$ (height SDS $=-4.2$ ) without GH treatment. The youngest brother (II.4) was treated for 9 years, initially

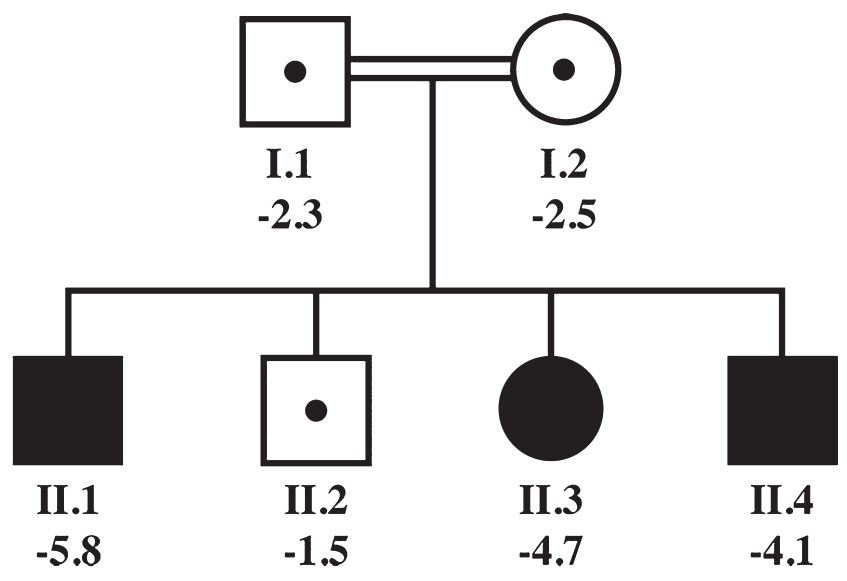

Figure 1

Family tree. The Arabic numbers indicate the height SDS of each individual at first visit. II.1, II.3 and II.4 are the affected siblings. Parents were first cousins. The filled black squares and circle represent the patients with IGHD, who are homozygous for both c. $-223 \mathrm{C}>\mathrm{T}$ and c. $-185 \mathrm{~T}>\mathrm{C}$. The squares and circle with a black dot represent the parents and the unaffected brother, who are heterozygous for both variants.

taking pituitary-GH $(0.1 \mathrm{mg} / \mathrm{kg} /$ week divided into equal daily doses given 3 days/week), followed by a daily dose of $0.33 \mathrm{mg} / \mathrm{kg}$ of human recombinant $\mathrm{GH}$ and $0.45 \mathrm{mg} / \mathrm{kg}$ during puberty; the youngest brother reached a final height of $161 \mathrm{~cm}$ (height SDS=-2.1). The patients spontaneously developed normal puberty, although the youngest one had pubertal development blocked for 1 year to achieve a greater final height. At adulthood (after the suspension of GH replacement), the patients were submitted to insulin tolerance tests, which confirmed isolated GH deficiency ( $\mathrm{GH}$ responses ranging from 0.5 to $2.5 \mu \mathrm{g} / \mathrm{L}$ by monoclonal antibody IFMA) (Supplementary Table 1). The three patients had normal pituitary at MRI, with eutopic posterior pituitary lobe, normal pituitary size and patent pituitary stalk.

\section{A double allelic variant in the proximal promoter region of growth hormone gene (GH1)}

The three affected siblings harboured four homozygous variations in GH1; these variants were described previously as rare heterozygous allelic variants. Two of the variants are located in intron 1 (c.53+52A>G: rs41318515 and c.53+56A $>$ T: rs41318516, cDNA reference sequence: NM_000515), and the other two are located in the GH1 promoter region (c.-223C >T: rs41295015 and c.-185T>C: 
rs71651677) (Supplementary Table 4). None of these variants were found in Exome Aggregation Consortium (ExAC) database (http://exac.broadinstitute.org). The patients did not present any genomic variants in the GHRHR gene, GH1 LCR, GH1 exons 1-5, or GH1 introns $2-4$. In addition, they harboured SNPs in the proximal promoter in homozygous state, described by Horan et al. as haplotype 8 (5). The allelic variant c. $-185 \mathrm{~T}>\mathrm{C}$ was reported previously by Millar et al. $(5,18)$ as c.-123T $>$ C . The HGVS recommendations (c.-223C $>\mathrm{T}$ : rs41295015 and c.-185T>C: rs71651677) were adopted through the manuscript.

The brother with normal stature was homozygous for variants c. $53+52 \mathrm{~A}>\mathrm{G}$ and c. $53+56 \mathrm{~A}>\mathrm{T}$, leading to the conclusion that these were not the genetic basis of isolated growth hormone deficiency in the siblings.

Although the variants c. $-223 \mathrm{C}>\mathrm{T}$ and c. $-185 \mathrm{~T}>\mathrm{C}$ were previously identified in controls, they have never been found in the homozygous state (18). Furthermore, the parents and brother with normal stature are heterozygous for both variants (Supplementary Fig. 1), and these changes were not observed among 200 Brazilian control alleles.

To understand the relevance of these variations, we performed in silico analysis using Alibaba2.1 available on TRANSFAC, which suggested that c.-223C is located within the binding site for the transcription factor SP1, while c.-185T is located in a binding site for the transcription factors POU1F1 and SP1. Moreover, in silico analysis also predicted that the c.-223C $>\mathrm{T}$ variant would lead to a loss of the SP1 binding site and c. $-185 \mathrm{~T}>\mathrm{C}$ would lead to a loss of the POU1F1 binding site, whereas the SP1 binding site would remain intact (Supplementary Fig. 2).

Interestingly, both variants are present in $G H 1$ paralogues; c. $-223 \mathrm{C}>\mathrm{T}$ is present in $\mathrm{GH} 2$ and $\mathrm{CS} 1$ sequences, c. $-185 \mathrm{~T}>\mathrm{C}$ is present in $\mathrm{GH} 2$ sequence (14).

\section{Decreased GH1 expression in the mutant}

Dual-luciferase reporter assays were performed to test the functional relevance of the c. $-223 \mathrm{C}>\mathrm{T}$ and c.-185T $>\mathrm{C}$ allelic variants associated with haplotype 8 . Plasmids containing the wild-type (-223WT/-185WT) and allelic variant sequences $(-223 \mathrm{AV} /-185 \mathrm{AV})$ were constructed, and GH3 cells from Dr Audrey Seasholtz were transiently transfected with these constructs. A basic pGL3 plasmid was used as blank control. The heterozygous variants (6) were simulated by simultaneously transfecting equal amounts of the $-223 \mathrm{WT} /-185 \mathrm{WT}$ and $-223 \mathrm{AV} /-185 \mathrm{AV}$
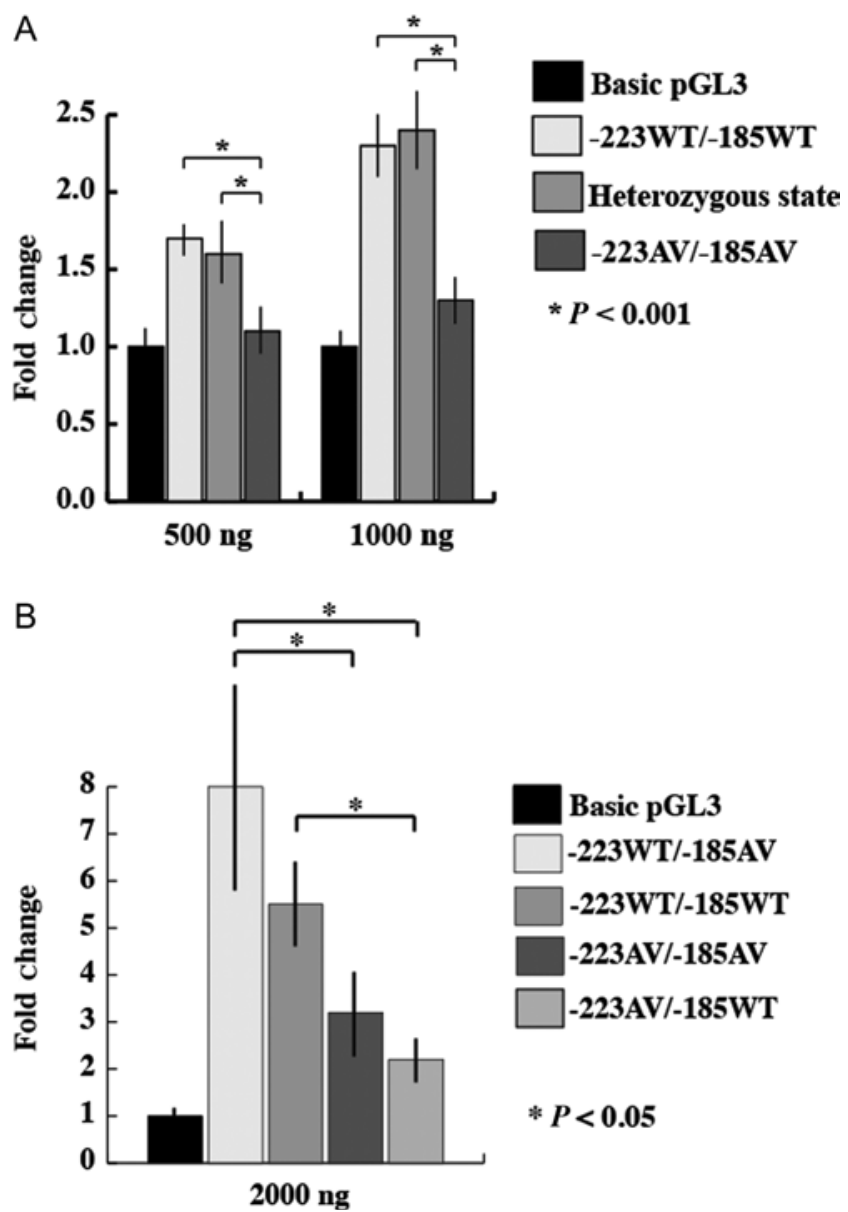

Figure 2

(A) Relative ability of GH1 promoter region variants to drive luciferase expression in the GH3 cell line from Dr Audrey Seasholtz. The results are expressed as the fold change over the basic pGL3 plasmid. To simulate the heterozygote (6), equal amounts of plasmid containing two wild-type (-223WT/185WT) and two variant alleles (-223AV/-185AV) were transfected, maintaining the total amount of plasmid DNA containing the $\mathrm{GH} 1$ promoter at $500 \mathrm{ng}$ or $1000 \mathrm{ng}$ as indicated on the x-axis. When transfecting a total amount of $500 \mathrm{ng}$ or $1000 \mathrm{ng}$ of plasmid DNA containing the GH1 promoter, -223AV/-185AV resulted in reduced luciferase expression compared with both -223WT/-185WT and HET. $* P \leq 0.001$. (B) GH3 cell line from $B C R J$ was transfected with $2000 \mathrm{ng}$ of plasmid DNA. The -223AV/-185WT construct resulted in significantly lower luciferase expression compared with both -223WT/-185WT and -223WT/-185AV, while -223WT/-185AV resulted in higher expression than -223WT/$185 \mathrm{WT}$ (although not statistically significant) and significantly higher than -223AV/-185AV, demonstrating that the c.-223C>T variant is deleterious but the c. $-185 \mathrm{C}>\mathrm{T}$ variant is not. 
constructs. GH3 cells are a rat cell line that expresses POU1F1 and SP1 and other nuclear transcriptional factors that are necessary for $G H 1$ expression.

A total of $500 \mathrm{ng}$ of plasmid DNA containing the GH1 promoter was transfected, and the heterozygous state was simulated with transfection of $250 \mathrm{ng}$ of $-223 \mathrm{WT} /-185 \mathrm{WT}$ and $250 \mathrm{ng}$ of $-223 \mathrm{AV} /-185 \mathrm{AV}$. The $-223 \mathrm{WT} /-185 \mathrm{WT}$ promoter drove significantly greater expression of luciferase compared with the $-223 \mathrm{AV} /-185 \mathrm{AV}$ variant promoter $(1.7 \pm 0.2$ vs $1.1 \pm 0.3, P \leq 0.001)$, although this amount was roughly equal to that of the simulated heterozygote (Fig. 2A). Similarly, the transfection of $1000 \mathrm{ng}$ of GH1 promoter plasmid DNA also led to greater expression of luciferase in cells transfected with -223WT/-185WT than cells transfected with $-223 \mathrm{AV} /-185 \mathrm{AV}(2.3 \pm 0.4$ vs $1.3 \pm 0.3, P \leq 0.001)$. However, this level was not greater than that attained by cells transfected with simulated heterozygous (which consisted of transfection of $500 \mathrm{ng}$ of $-223 \mathrm{WT} /-185 \mathrm{WT}$ and $500 \mathrm{ng}$ of $-223 \mathrm{AV} /-185 \mathrm{AV})(2.3 \pm 0.4$ vs $2.4 \pm 0.5, P=0.609$ ) (Fig. $2 \mathrm{~A}$ ).

To evaluate the effect of c. $-223 \mathrm{C}>\mathrm{T}$ and c. $-185 \mathrm{~T}>\mathrm{C}$ variants on phenotype individually, plasmids containing mutation only at position c.-223 (-223AV/-185WT) and only at position c.-185 (-223WT/-185AV) were constructed, and GH3 cell line from BCRJ was employed. Transfection of $2000 \mathrm{ng}$ of $-223 \mathrm{AV} /-185 \mathrm{WT}$ plasmid DNA resulted in significantly lower luciferase activity compared with both -223WT/-185WT $(2.2 \pm 0.9$ vs $5.5 \pm 1.8, P=0.001)$ and $-223 \mathrm{WT} /-185 \mathrm{AV}(2.2 \pm 0.9$ vs $8.0 \pm 4.3, P=0.016$; Fig. $2 \mathrm{~B})$, while $-223 \mathrm{WT} /-185 \mathrm{AV}$ drove significantly higher expression than $-223 \mathrm{AV} /-185 \mathrm{AV}(8.0 \pm 4.3$ vs $3.2 \pm 1.8, P=0.016)$. Although the expression of $-223 \mathrm{WT} /-185 \mathrm{AV}$ was higher than $-223 \mathrm{WT} /-185 \mathrm{WT}(8.0 \pm 4.3$ vs $5.5 \pm 1.8, P=0.086)$ and the expression of $-223 \mathrm{AV} /-185 \mathrm{WT}$ was lower than $-223 \mathrm{AV} /-185 \mathrm{AV}(2.2 \pm 0.9$ vs $3.2 \pm 1.8, P=0.067)$, neither of these differences were statistically significant (Fig. 2B).

\section{EMSA demonstrated that c. $-223 \mathrm{C}>\mathrm{T}$ leads to the loss of GH3 nuclear extract binding site, while c.-185T>C does not affect SP1/POU1F1 binding sites}

Because c.-223C $>\mathrm{T}$ led to decreased GH1 expression, an electrophoretic mobility shift assay (EMSA) was performed to determine whether the variants c. $-223 \mathrm{C}>\mathrm{T}$ and c.-185T>C would lead to loss of the interaction between transcriptional factors and the GH1 promoter region.

To study the impact of the c. $-223 \mathrm{C}>\mathrm{T}$ variant, probes containing the wild-type c.-223 (-223WT) sequence and the variant $(-223 \mathrm{AV})$ were incubated with a nuclear extract of GH3 cells (Supplementary Table 3). As expected, the -223WT probe interacted with the GH3 nuclear extract, forming a labelled band (Fig. 3); this band was specific, as it was completely cleared by the addition of increasing amounts of unlabelled wild-type probe. The interaction between the GH3 nuclear extract and the $-223 \mathrm{AV}$ probe did not result in any labelled band, suggesting that

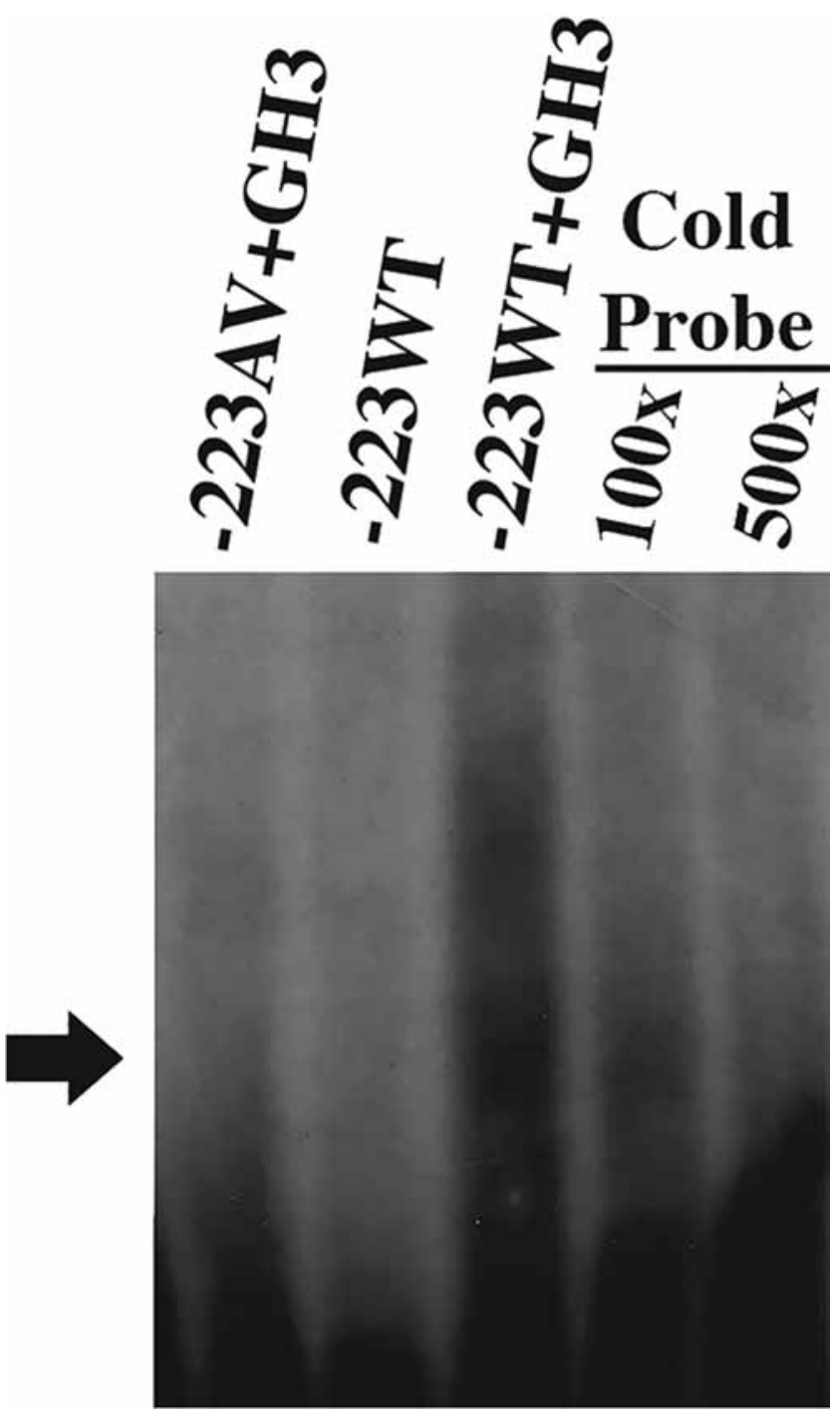

Figure 3

Electrophoretic mobility shift assay (EMSA) using GH3 nuclear extract and GH1 promoter probes for the position c.-223 containing the wild-type (-223WT) and the variant (-223AV) sequences. The arrow indicates a specific complex between the $-223 \mathrm{WT}$ and the nuclear extract that is completely cleared by competition with increasing amounts of unlabelled -223WT (cold probe, fourth and fifth columns). Probe -223AV did not form a labelled band with GH3 nuclear extract, demonstrating that the c.-223C>T variant leads to a loss of interaction between nuclear transcription factors and the $\mathrm{GH} 1$ promoter. 
c.-223C > T leads to a loss of the interaction between nuclear transcription factors and the $G H 1$ promoter.

The impact of c.-185T>C was examined using probes containing the wild-type (-185WT) sequence and the allelic variant (-185AV) at position c.-185 and a GH3 nuclear extract (Supplementary Table 3). The GH3 nuclear extract and the wild-type probe formed a specific complex, which was totally cleared by competition with increasing amounts of unlabelled wild-type probe. This complex was formed between the GH3 nuclear extract and the mutant probe (Fig. 4).

Purified POU1F1 protein, as well as -185WT and $-185 \mathrm{AV}$, were used to test whether c.-185T $>\mathrm{C}$ has a specific effect on the interaction between POU1F1 and the GH1 promoter as suggested by Alibaba2.1. POU1F1

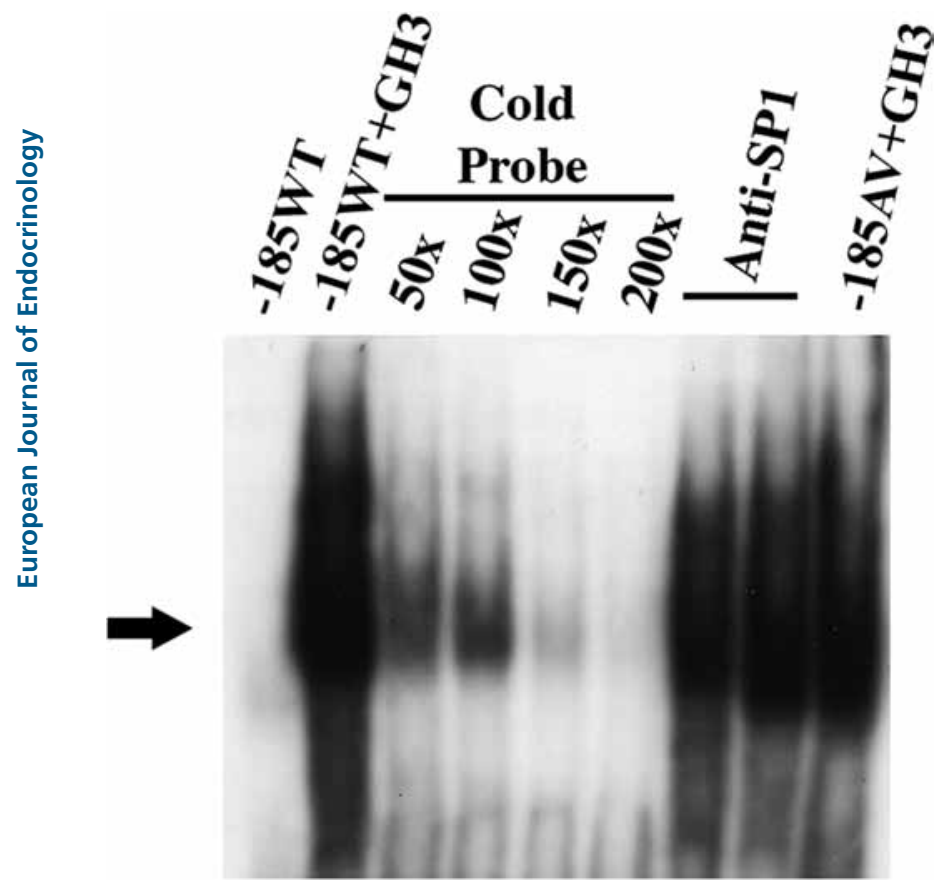

Figure 4

Electrophoretic mobility shift assay (EMSA) using GH3 nuclear extract and GH1 promoter probes for the position c.-185 containing the wild-type (-185WT) and the variant (-185AV) sequences. The arrow indicates a specific complex between the wild-type probe and the nuclear extract that is completely cleared by competition with increasing amounts of unlabelled wild-type probe (cold probe) (third to sixth columns).

Furthermore, the addition of an anti-SP1 antibody did not lead to a supershift or clear the labelled band (seventh and eighth columns), indicating that SP1 is either not present in this complex or present in a small amount. The interaction between the GH3 nuclear extract and -185AV was preserved.

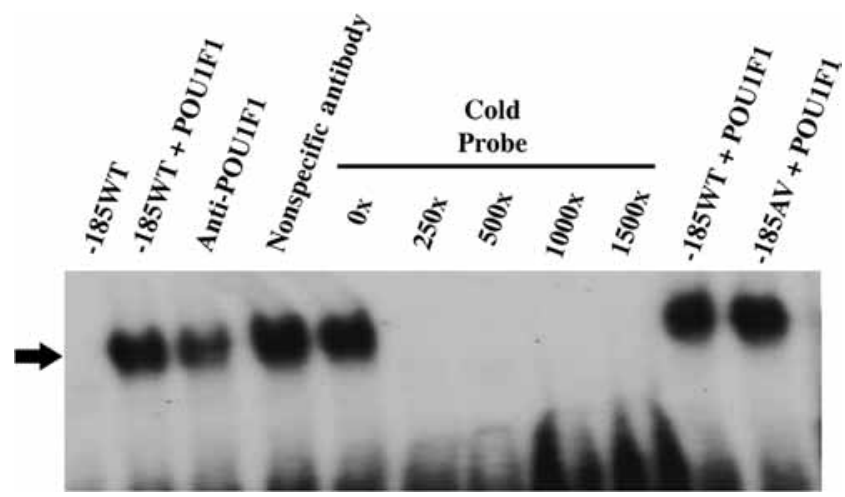

\section{Figure 5}

Electrophoretic mobility shift assay (EMSA) using GH3 nuclear extract and $\mathrm{GH} 1$ promoter probes for position c.-185 containing the wild-type (-185WT) and the variant (-185AV) sequences. The arrow indicates a specific complex formed between the wild-type probe and the purified protein that is partially cleared by the addition of a specific antibody against POU1F1 (third column) but not by a non-specific antibody (fourth column). This complex was totally cleared by competition with unlabelled -185WT (cold probe) (fifth to ninth columns). The interaction between POU1F1 and -185AV was preserved.

and -185WT interacted with each other in a complex (Fig. 5) that was partially cleared by the addition of an anti-POU1F1 antibody but not by the addition of a nonspecific antibody, indicating that the interaction was specific. Moreover, increasing amounts of unlabelled wildtype probe also eliminated this complex. A comparison of the $-185 \mathrm{WT} / \mathrm{POU} 1 \mathrm{~F} 1$ and $-185 \mathrm{AV} / \mathrm{POU} 1 \mathrm{~F} 1$ complexes showed no significant differences (Fig. 5), suggesting that the POU1F1 binding site was preserved.

\section{Discussion}

Although several studies have described genetic variations in the GH1 promoter region and their effect on GH1 expression $(5,12,13,14,15,16,17,18)$, a point mutation in the promoter region that leads to IGHD with complete penetrance has never been found.

In this study, we investigated the genetic basis of IGHD type IB in three siblings born to consanguineous parents. The patients had promoter haplotype 8 , based on the nomenclature defined by Horan et al.; this haplotype was described previously as being homozygous in normal controls (5). In addition to this haplotype, the patients harboured four homozygous variations in the $G H 1$ promoter that were described previously as rare 
heterozygous allelic variants. Two of these variations were found in intron 1 (c.53+52A>G: rs41318515 and c. $53+56$ A $>$ T: rs41318516) and were homozygous in the brother with normal stature, suggesting that they did not lead to IGHD in the affected siblings.

The other two variations (c.-223C>T: rs41295015 and c.-185T>C: rs71651677) were found in the GH1 promoter region, and both fall within two conserved transcription factor binding sites. Although these variations have been described in normal controls (18), they have not been described as being homozygous and have never been described together.

In our study, a promoter construct containing both variations resulted in significantly reduced expression of luciferase. Furthermore, the luciferase activity was similar in the transfection of both -223WT/-185WT and HET, suggesting that there is no dominant negative effect.

Interestingly, Millar et al. showed that the variant c.-185T $>$ C did not lead to reduced luciferase expression in a transient transfection assay. In fact, this variant caused an increase (153\%) in luciferase activity in GC cells relative to the wild type (18).

Our findings are consistent with those of Millar et al. (18) because the plasmid -223AV/-185WT showed significantly reduced expression of luciferase compared with -223WT/-185WT and to -223WT/-185AV. Meanwhile -223WT/-185AV drove higher expression than -223AV/-185AV and -223WT/-185WT (although the difference in the expression drove by -223WT/-185AV and by $-223 \mathrm{WT} /-185 \mathrm{WT}$ was not statistically significant), suggesting that the c.-185T $>\mathrm{C}$ variant does not have a negative effect.

The c.-223C>T variant has also been shown to negatively affect the interaction between the GH1 promoter region and nuclear transcription factors (i.e. those present in the GH3 nuclear extract), suggesting that this variant decreases $G H 1$ expression due to the loss of this interaction. Nucleotide $\mathrm{C}$ at this position is well conserved through human, Rhesus, dog and elephant, although it is not conserved in mice, which present a guanine $(G)$ at this position according to UCSC genome browser (https://genome.ucsc.edu/cgibin/hgTracks?db=hg38\&las tVirtModeType $=$ default\&lastVirtModeExtraState $=\&$ virtM odeType $=$ default $\&$ virtMode $=0 \&$ nonVirtPosition $=\&$ posit ion=chr17\%3A6391899963918999\&hgsid=488898305_ DGErgACOe8309wySteAdlnTqUTk4).

Although c.-185T $>C$ was predicted to be located in the binding site for POU1F1 and SP1 based on Alibaba2.1 analysis, EMSA did not indicate the loss of an interaction between -185AV and GH3 nuclear extract or purified
POU1F1 protein, suggesting that this variant is not deleterious.

In this context, c.-223C $>\mathrm{T}$ is the deleterious variant that likely leads to IGHD type IB in the three affected siblings.

Position c.-223 is located at the predicted binding site for SP1 according to Alibaba2.1 analysis and, according to in silico prediction, the mutation c.-223C>T would lead to loss of SP1 binding to GH1 promoter. The transcriptional factor SP1 may act as either activator or repressor of gene expression depending on numerous variants as cell type, concentration of other intracellular proteins such as SP3 and post-translational modifications of SP1 protein, i.e. glycosylation, phosphorylation and sumoylation $(8,22)$. Although SP1 is considered a repressor of GH1 expression, as interaction between SP1 and its binding site located at c.-163 of GH1 promoter decreases GH1 expression (8), interaction between SP1 and the binding site located at c.-223 was not previously studied, and at this position, SP1 could act stimulating GH1 expression. Moreover, in silico analysis may have not identified other activator transcriptional factors that bind to GH1 promoter at c.-223. Further studies are necessary to clarify the role of SP1 as a regulator of somatotroph GH1 expression and the transcriptional factors that bind to GH1 promoter at c. -223 .

To our knowledge, this is the first report of a point mutation in the GH1 promoter region associated with IGHD with complete penetrance, expanding the molecular aetiology of IGHD type IB and reinforcing the role of the promoter region as a major regulator of $G H 1$ expression.

\section{Supplementary data}

This is linked to the online version of the paper at http://dx.doi.org/10.1530/ EJE-15-0149.

\section{Declaration of interest}

The authors declare that there is no conflict of interest that could be perceived as prejudicing the impartiality of the research reported.

\section{Funding}

This work was supported by grants from Fundação de Amparo a Pesquisa do Estado de São Paulo - FAPESP (2010/05188-0 to J L M and L R C and 2013/03236-5 to A A L J) and from Conselho Nacional de Desenvolvimento Científico e Tecnológico - CNPq (301339/2008-9 to B B M; 300982/2009-7 to I J P A and 304678/2012-0 to A A L J).

Author contribution statement

Joao L O Madeira wrote the paper and performed the functional study. Regina M Martin, Luciana R Montenegro and Marcela M França are 
responsible for sequencing GH1, GHRH and GHRHR in this family. Everlayny F Costalonga, Fernanda A Correa and Aline P Otto contributed with clinical follow-up. Helayne $S$ Freitas and Ubiratan $F$ Machado performed EMSA experiments. Alexander A L Jorge, Ivo J P Arnhold, Berenice B Mendonça and Luciani R S Carvalho are supervisors.

\section{Acknowledgements}

We would like to acknowledge Fundação de Amparo a Pesquisa do Estado de São Paulo - FAPESP and Conselho Nacional de Desenvolvimento Científico e Tecnológico - CNPq for financial support. We are also grateful to Prof. Ubiratan's group, who performed the EMSA experiments, Dr Vinicius Nahime Brito for statistical analysis interpretation and our colleagues at LIM42 - Hospital das Clínicas for their support and friendly relationship.

\section{References}

1 Duquesnoy P, Roy A, Dastot F, Ghali I, Teinturier C, Netchine I, Cacheux V, Hafez M, Salah N, Chaussain JL et al. Human Prop-1: cloning, mapping, genomic structure. Mutations in familial combined pituitary hormone deficiency. FEBS Letters 1998437 216-220. (doi:10.1016/S0014-5793(98)01234-4)

2 Chen EY, Liao YC, Smith DH, Barrera-Saldaña HA, Gelinas RE \& Seeburg PH. The human growth hormone locus: nucleotide sequence, biology, and evolution. Genomics 19894 479-497. (doi:10.1016/08887543(89)90271-1)

3 Phillips JA, Hjelle BL, Seeburg PH \& Zachmann M. Molecular basis for familial isolated growth hormone deficiency. PNAS 198178 6372-6375.

4 Mullis PE. Genetics of isolated growth hormone deficiency. Journal of Clinical Research in Pediatric Endocrinology 20102 52-62. (doi:10.4274/ jcrpe)

5 Horan M, Millar DS, Hedderich J, Lewis G, Newsway V, Mo N, Fryklund L, Procter AM, Krawczak M \& Cooper DN. Human growth hormone 1 (GH1) gene expression: complex haplotype-dependent influence of polymorphic variation in the proximal promoter and locus control region. Human Mutation 200321 408-423. (doi:10.1002/ humu.v21:4)

6 Giordano M, Marchetti C, Chiorboli E, Bona G \& Momigliano Richiardi P. Evidence for gene conversion in the generation of extensive polymorphism in the promoter of the growth hormone gene. Human Genetics 1997100 249-255. (doi:10.1007/ s004390050500)

7 Wagner JK, Eble A, Cogan JD, Prince MA, Phillips JA 3rd \& Mullis PE. Allelic variations in the human growth hormone- 1 gene promoter of growth hormone-deficient patients and normal controls. European Journal of Endocrinology 1997137 474-481. (doi:10.1530/ eje.0.1370474)

8 Vines CR \& Weigent DA. Identification of SP3 as a negative regulatory transcription factor in the monocyte expression of growth hormone. Endocrinology 2000141 938-946. (doi:10.1210/endo.141.3.7381)

9 Courtois SJ, Lafontaine DA, Lemaigre FP, Durviaux SM \& Rousseau GG. Nuclear factor-I and activator protein-2 bind in a mutually exclusive way to overlapping promoter sequences and transactivate the human growth hormone gene. Nucleic Acids Research 199018 57-64. (doi:10.1093/nar/18.1.57)

10 Ingraham HA, Chen RP, Mangalam HJ, Elsholtz HP, Flynn SE, Lin CR, Simmons DM, Swanson L \& Rosenfeld MG. A tissue-specific transcription factor containing a homeodomain specifies a pituitary phenotype. Cell 198855 519-529. (doi:10.1016/0092-8674(88)90038-4)
11 Jin Y, Surabhi RM, Fresnoza A, Lytras A \& Cattini PA. A role for A/T-rich sequences and Pit-1/GHF-1 in a distal enhancer located in the human growth hormone locus control region with preferential pituitary activity in culture and transgenic mice. Molecular Endocrinology 199913 1249-1266. (doi:10.1210/mend.13.8.0332)

12 Giordano M, Godi M, Giacopelli F, Lessi M, Mellone S, Paracchini R, Petri A, Bellone J, Ravazzolo R, Bona G et al. A variation in a Pit-1 site in the growth hormone gene (GH1) promoter induces a differential transcriptional activity. Molecular and Cellular Endocrinology 2006249 51-57. (doi:10.1016/j.mce.2006.01.006)

13 Giordano M, Godi M, Mellone S, Petri A, Vivenza D, Tiradani L, Carlomagno Y, Ferrante D, Arrigo T, Corneli G et al. A functional common polymorphism in the vitamin D-responsive element of the GH1 promoter contributes to isolated growth hormone deficiency. Journal of Clinical Endocrinology \& Metabolism 200893 1005-1012. (doi:10.1210/jc.2007-1918)

14 Esteban C, Audi L, Carrascosa A, Fernandez-Cancio M, PerezArroyo A, Ulied A, Andaluz P, Arjona R, Albisu M, Clemente M et al. Human growth hormone (GH1) gene polymorphism map in a normal-statured adult population. Clinical Endocrinology 200766 258-268. (doi:10.1111/cen.2007.66.issue-2)

15 Birla S, Jyotsana PV, Sharma A, Khadgawat R, Garg M \& Jain V. Genetic characterization of growth hormone 1 gene in patients with isolated growth hormone deficiency. Indian Journal of Endocrinology and Metabolism 16 (Supplement 2) S310-S312.

16 de Graaff LC, Argente J, van Meurs JB, Uitterlinden AG \& HokkenKoelega AC. Genetic polymorphisms in the locus control region and promoter of GH1 are related to serum IGF-I levels and height in patients with isolated growth hormone deficiency and healthy controls. Hormone Research in Paediatrics 201073 25-34. (doi:10.1159/000271913)

17 Rojas-Gil AP, Ziros PG, Kanetsis E, Papathanassopoulou V, Nikolakopoulou NM, He K, Frank SJ, Papavassiliou AG \& Spiliotis BE. Combined effect of mutations of the GH1 gene and its proximal promoter region in a child with growth hormone neurosecretory dysfunction (GHND). Journal of Molecular Medicine 200785 1005-1013. (doi:10.1007/s00109-007-0200-7)

18 Millar DS, Lewis MD, Horan M, Newsway V, Easter TE, Gregory JW, Fryklund L, Norin M, Crowne EC, Davies SJ et al. Novel mutations of the growth hormone 1 (GH1) gene disclosed by modulation of the clinical selection criteria for individuals with short stature. Human Mutation 200321 424-440. (doi:10.1002/(ISSN)1098-1004)

19 Silva EG, Slhessarenko N, Arnhold IJ, Batista MC, Estefan V, Osorio MG, Marui S \& Mendonca BB. GH values after clonidine stimulation measured by immunofluorometric assay in normal prepubertal children and GH-deficient patients. Hormone Research 200359 229-233. (doi:10.1159/000070222)

20 Osorio MG, Marui S, Jorge AA, Latronico AC, Lo LS, Leite CC, Estefan V, Mendonca BB \& Arnhold IJ. Pituitary magnetic resonance imaging and function in patients with growth hormone deficiency with and without mutations in GHRH-R, GH-1, or PROP-1 genes. Journal of Clinical Endocrinology \& Metabolism 200287 5076-5084. (doi:10.1210/jc.2001-011936)

21 Freitas HS, Schaan BD, David-Silva A, Sabino-Silva R, Okamoto MM, Alves-Wagner AB, Mori RC \& Machado UF. SLC2A2 gene expression in kidney of diabetic rats is regulated by HNF-1alpha and HNF-3beta. Molecular and Cellular Endocrinology 2009305 63-70. (doi:10.1016/j. mce.2009.02.014)

22 Gong L, Ji WK, Hu XH, Hu WF, Tang XC, Huang ZX, Li L, Liu M, Xiang SH, Wu E et al. Sumoylation differentially regulates Sp1 to control cell differentiation. PNAS 2014111 5574-5579. (doi:10.1073/ pnas.1315034111)

Received 9 February 2015

Revised version received 26 May 2016

Accepted 31 May 2016 